\title{
Reflections on Museum Curation
}

\author{
Ling Wan \\ Wuhan Revolutionary Museum \\ Wuhan, P.R.China
}

\begin{abstract}
With the rapid development of museum undertakings, it plays an increasingly significant role in the public culture and society. That exhibitions design not only attract the public but also lead the public is a pressing issue that we need to think about. Combined with individual experiences and reflections on exhibition design, this article, in terms of prominent problems, aims at offering some thoughts and analysis for three aspects: theme, narrative thinking and audiences of exhibition.
\end{abstract}

\section{Keywords—museum; exhibition design; thinking}

\section{INTRODUCTION}

Working for relics and museology over a decade, the author participated in design planning of displays and exhibitions, and visited a variety of museums with diverse styles, themes, and levels of at home and abroad. However, when visiting Chinese museums, there are always something familiar, especially in design techniques, materials, etc. There are three fundamental reasons. First of all, there is no innovation in the exhibition design. Essentially speaking, the design company lacks the ability to excavate of the connotation of the exhibition, which fails the conversion from text to form. Secondly, the conception of the exhibition is ordinary without the core competitive capacity, which is the radical weakness. Last but not least, with regard to artistic language expression in the exhibition, attractive design is necessity to convey the theme and connotation of the exhibition.

Exhibitions design should achieve the combination of attraction and guide, which is an urgent issue that we have to consider. Combined with individual experiences and in exhibition design, this article is expected to give analysis of design in exhibitions.

\section{CORE CONCEPT OF EXHIBITION DESIGN}

Strictly speaking, design related to textual planning is one of principles in museum exhibition design. Text is one of the major methods of interpretation-orientation in the exhibition language, but it is not enough to design based on texts. In terms of exhibition, "language" and "mode" is singularly important. Character is the representation of transmission of ideas and information, not a result. Therefore, from a professional standpoint of the text, problems remaining to be solved have covered of form design. To some extent, text planners need to convey accurate information to all the people participating in the exhibition about what to do, how to do it and its purpose. This is the bottom line of exhibition planning. Form design should be based on textual planning solve problems.

The core of exhibition design is to express the theme of the exhibition, which is a dominant factor that constitutes the exhibition. It reveals the interrelationship among cultural relics and vavious elements that constitutes the exhibition. Then, what is the source of the topic? How did the topic come about? Is the topic a prompt product of brainstorming? Obviously not. As a matter of fact, theme comes from curator's profound study of the collection, the keen sense of times, the unique perspective of displaying art, master in mass psychology, as well as the comprehensive considerations based on social, political, and economic needs of modern society, which shows curators' comprehensive capabilities. Displayed through different array mode, order and priprity, the same batch of collections can fully appear on the exhibition with various themes.

At this point, I highly praise Mr. Su Donghai's views on the basic functions of the museum, he thinks that "The three functions of the museum are in turn appearing in the history of the museum. The collection of objects is the first function, the second function that emerges is the research function, and the last is the education function. The center of circle is the collection of objects, the inner circle is scientific research, and the outer circle is education. "The collection is an important component of the museum, it is the foundation and starting point for the museum to carry out all its business work, and it is also the lifeblood of the existence and development of the museum. Therefore, the formation of the core idea of exhibition design requires us to pay attention to the collection itself through text. A museum is a history of materialization, carrying a wealth of information and being quite persuasive and infectious. Through the dialogue between collections and history, the exhibition crosses time and space, fully and accurately reflects the development history of a certain social history, and so on. The theme exhibition based on the collections needs the planners to have solid historical and cultural knowledge, theories and methods, and to have a great historical view and big art view, which requires a certain degree of philosophy. More importantly, the exhibition also has dialogues with people through collections. All the collections are also the "things" left by past experience and innovations and actions completed by "humans" in the past time and space. We cannot leave people to see things, nor can we leave things to see people. The exhibition is a process of linking past objects with present people. In addition, in order to express the different levels and interactions of topics and even sub- 
themes, the core ideas of exhibition design are also diversified, depending on the perspective and perspective of the designer. Take the historic exhibition as an example, we can truly restore the historical scene, and we can also show the many causes of these historical phenomena; the history can be described by elite figures, and the path of civilians can also be taken.

In short, the core idea of exhibition design should be consistent with the internal system of the collection, accurately reveal the theme, and strive to maximize the audience's approval.

\section{ThE EXHIBITION DESIGN NEEDS TO BE LINKED BY CONSECUTIVE STORY LINES}

To recognize this point, I am more from the perspective of visitors to museum exhibitions. In fact, storytelling is a kind of human intelligence. A story can describe the context of events. Listening to stories is human nature. It is a way for humans to convey memories, experiences, and wisdom. People try to reproduce the original appearance of events and feel the meaning of the information behind them. The story is often characterized by coherence, attractiveness, and appeal. It has popular, easy-to-remember features and excellent communication effects. The classic works of Greek mythology and Aesop's fables are all genres of the story. The audience uses the "story" to interpret the exhibits. "Museum exhibitions should use their own audience as the measure standard, construct an exhibition framework for the exhibits, extend a story line, and add cognitive and educational elements to the story line so that the exhibition is integrated and the plot is extended enough to help viewers use and understand the content of exhibits better."

It can be seen that the exhibition plays the most direct role in the dissemination of knowledge and transmission of information. But what is the ultimate goal? It is to focus on the people, and their feelings. To be exact, the ultimate goal is to connect visitors with actuality during their visits. Each item of the exhibition is expressed by a story, through which visitors can get various understandings and emotional experiences by combining their actual feelings or thoughts. From the view of the development trend of museum exhibition, what matters more should be the guidance of value. In the future, the value education should be taken into consideration for the exhibitions in museums. So how to achieve it? At present, in the compiling of the large-scale thematic exhibition, "Discipline Building is Always on The Road", political preaching should be avoided in the exhibition content, or it might make it a bad play for the writer, an empty explanation for the social education stuff, an unattractive exhibition for the audience. However, it remains a question how to describe it vividly and infectiously. Undoubtedly, the vivid stories of Communist Party members have special attractiveness and infection for the public who know nothing about them. Therefore, it is the main point and will be the highlight for exhibition to dig out and demonstrate some typical stories. For example, in the story of "The Taste of Faith", totally buried in the translation of Manifesto of the Communist Party, Chen Wangdao took the ink as sugar and ate it unconsciously, and even felt that the ink was much more sweet. This has revealed the theme that the Communist Party members are determined to seek for truth, abide to faith, and achieve the goals. In the compiling of the program, such stories exist all the time, and have remained the key point to attract the attention of visitors.

Sometimes, a coherent storyline can also be the exhibition line for the museum. It has been proved to be one of the most effective ways for exhibition to create background stories to present the audience. The Math Museum of the Chicago Museum of Science and Industry is a classic example of a story line. It is said that 3 years' early academic research including 11 exhibition items has been prepared for the 320 square meters of exhibition hall. For instance, some basic mathematical principles such as probability curves, multiplication tables, motion and the law of gravity, etc., constitute the whole exhibition with many a knowledge point. In the items of exhibition, each knowledge point is studied in depth; in the techniques of exhibition, the exhibition space is built into a laboratory, or a science carnival by means of devices, moving items, drawings and photos; what's more, the museum has also reshaped a 19thcentury street, allowing people to experience the interrelationship and development of mathematics, time, and life naturally, and allowing viewers to understand scientific common sense and mathematical knowledge from the context of life, and then appreciate the whole process of creation.

\section{EXHIBITION DESIGN SHOULD TAKE THE THOUGHTS AND FEELINGS OF THE VISITORS INTO ACCOUNT}

The first national legal document of the museum industry, "Museum Regulations", which has been officially implemented since 2015, states in Chapter one, "General principles," that "museums" as mentioned in these regulations refer to non-profit organizations registered by the registration administration authority in accordance with the law, which collect, protect and display to the public the evidence of human activities and the natural environment in the purpose of education, research and appreciation. This means that our country is formally in line with the international community and has made a readjustment of the three major purposes of museums to put education in the first place. Although this is a minor amendment to the definition of "museum", it will undoubtedly affect the overall operation of the museum in the future in our country.

As the audience of the museum, the public's experiences and feelings are extremely important and challenging for us museum members as we must satisfy the individual needs of the audience, and meanwhile play a role in the dissemination of the museum culture, value guidance and social influence. The standard for measuring the effectiveness of the exhibition lies not only in the number of audience, but more importantly, in the changes the exhibition brings to the public. Therefore, three basic needs of the audience must be 
considered in the design: cognitive needs, sacred feelings, and cultural experiences 1 .

Museum exhibitions must arouse the curiosity of the audience because the proportion of experts and professionals in the audience is less than $1 \%$. The kind of exhibition that satisfies leaders and experts may not necessarily gain public recognition. According to the theory of intrinsic motivation to promote behavior, the exhibition must arouse the curiosity of the audience, or match the audience's cognitive structure to the maximum extent, among which it is extremely important to induce audiences to think and act. For example, if we need to design an exhibition that introduces geological structures, scientific information is abundant, exhibition items are adequate and operating facilities for people to explore and master specialized skills are also set up. But the key point is: What is the relationship between this exhibition item and visitors? Can it help the audience understand the earth? If these questions cannot be answered, then the design of this exhibition item is mediocre, because the information it provides will not leave any impression in the minds of visitors.

The design of exhibition items originates from the purpose of producing results after communicating with the audience. In addition to perceptions and impressions, it is more important to design the exhibition items in order to guide the audience to produce more and more complex emotions and experiences. Of course, there is a major relationship between these and the content of the exhibition, which is also known as the starting point of the exhibition.

"At the museum's exhibition, our aim is to explore the possibility of using simpler technologies to expand the activities of visitors for the first step...... More emphasis is put on the interaction between people in the exhibition the minimization of the side effects of technology. "2 Therefore, designers should start from the space and think about the psychological feelings brought by museum exhibition themes and contents and to make each exhibition element obey the overall planning from overall to local arrangements, colors, words, pictures, equipment, props, landscapes, models, lighting, lighting, sound, each aspect of the imagery, greening, etc. When the audience is interested in the exhibition items and communicates with them through the senses, he will experience the beauty of creation and the exhibition hall will also be a place of sensation to the soul.

"Experience" is actually a beautiful feeling in a person's consciousness when he reaches a certain level of emotions, physical strength, intelligence, even spirituality... Nowadays, compared with the technological content of exhibitions, people are paying more attention to the emotional pleasure and satisfaction brought by exhibition. Museum exhibitions based on experience concepts should become the mainstream of museum display design in the new era. People get a kind of cultural experience and real feelings while getting information on exhibits.

\section{CONCLUSION}

In short, a high-quality display exhibition needs first have a core idea. In the design of the exhibition content, it is necessary to rely on the story line. And the most important thing is that the exhibition design should take into account the audience's experience and feelings in the visit. Besides, exhibition planning involves comprehensive knowledge of aesthetics, collections of cultural relics, high-tech display methods, exhibition environment and psychology. It is not only a systematic project, but also a project in the course of progress and exploration. Therefore, to arrange well an exhibition, whether it is content planning or artistic design, whether it is the preservation of cultural relics or social education, everyone needs to establish a mature knowledge system and comprehensive analysis, and considerations need to be done from all aspects of exhibition. Thus the plan can be both attractive and appealing, satisfying the audience's individual needs as well as achieving value leadership.

\section{REFERENCES}

[1] Yao An, 12 Lessons of Museum[M], Science Press, 2010

[2] Su Donghai, The Contemplation of the Museum - the Selection of Su Donghai's Papers (Vol. three)[M] , Heritage Press, 2010.

[3] American Museum Association, Museum Education and Learning[M], Beijing, Foreign Language Press, 2014.

[4] Smithsonian Policy and Analysis Office, For Tomorrow's Course: Smithsonian Educational Research[M], Jinan University Press, 2014.

[5] Zheng Yi, The Museum Education Research Activities, Fudan University press, 2015.
This is the point made by George F Macdonald, the former curator of the Canadian Museum of Civilisation (CMC).

2 Su Donghai: "Museum Contemplation—_-Selection of $\mathrm{Su}$ Donghai's Paper (Volume 3)", Heritage Press 2010, p. 368. 